\title{
A Physiologically Based Pharmacokinetic Model for Predicting Diazepam Pharmacokinetics after Intravenous, Oral, Intranasal, and Rectal Applications
}

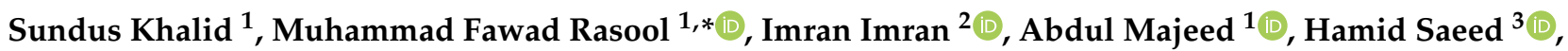 \\ Anees ur Rehman ${ }^{1}\left(\mathbb{D}\right.$, Waseem Ashraf ${ }^{2}$, Tanveer Ahmad ${ }^{4}\left(\mathbb{D}\right.$, Yousef A. Bin Jardan ${ }^{5}$ and Faleh Alqahtani ${ }^{6, *}(\mathbb{C})$ \\ 1 Department of Pharmacy Practice, Faculty of Pharmacy, Bahauddin Zakariya University, \\ Multan 60800, Pakistan; sunduskhalid.sk@gmail.com (S.K.); abdulmajeed@bzu.edu.pk (A.M.); \\ aneesurrehman@bzu.edu.pk (A.u.R.) \\ 2 Department of Pharmacology, Faculty of Pharmacy, Bahauddin Zakariya University, Multan 60800, Pakistan; \\ imran.ch@bzu.edu.pk (I.I.); chishtiwaseem@yahoo.com (W.A.) \\ 3 Section of Pharmaceutics, University College of Pharmacy, Allama Iqbal Campus, University of the Punjab, \\ Lahore 54000, Pakistan; hamid.pharmacy@pu.edu.pk \\ 4 Institute for Advanced Biosciences (IAB), Centre National de la Recherche Scientifique, Unite Mixte de \\ Recherche 5309, Institut National de la Sante et de la Recherche Medicale U1209, Grenoble Alpes University, \\ 38700 La Tronche, France; tanveer.ahmad@univ-grenoble-alpes.fr \\ check for \\ updates \\ Citation: Khalid, S.; Rasool, M.F.; \\ Imran, I.; Majeed, A.; Saeed, H.; \\ 5 Department of Pharmaceutics, College of Pharmacy, King Saud University, Riyadh 11451, Saudi Arabia; \\ ybinjardan@ksu.edu.sa \\ 6 Department of Pharmacology and Toxicology, College of Pharmacy, King Saud University, \\ Riyadh 11451, Saudi Arabia \\ * Correspondence: fawadrasool@bzu.edu.pk (M.F.R.); afaleh@ksu.edu.sa (F.A.)
}

Rehman, A.u.; Ashraf, W.; Ahmad, T.; Bin Jardan, Y.A.; Alqahtani, F. A

Physiologically Based

Pharmacokinetic Model for

Predicting Diazepam

Pharmacokinetics after Intravenous,

Oral, Intranasal, and Rectal

Applications. Pharmaceutics 2021, 13,

1480. https://doi.org/10.3390

/pharmaceutics13091480

Academic Editor: Yu Chul Kim

Received: 18 August 2021

Accepted: 13 September 2021

Published: 15 September 2021

Publisher's Note: MDPI stays neutral with regard to jurisdictional claims in published maps and institutional affiliations.

Copyright: ( $\odot 2021$ by the authors. Licensee MDPI, Basel, Switzerland. This article is an open access article distributed under the terms and conditions of the Creative Commons Attribution (CC BY) license (https:// creativecommons.org/licenses/by/ $4.0 /)$.

\begin{abstract}
Diazepam is one of the most prescribed anxiolytic and anticonvulsant that is administered through intravenous (IV), oral, intramuscular, intranasal, and rectal routes. To facilitate the clinical use of diazepam, there is a need to develop formulations that are convenient to administer in ambulatory settings. The present study aimed to develop and evaluate a physiologically based pharmacokinetic (PBPK) model for diazepam that is capable of predicting its pharmacokinetics (PK) after IV, oral, intranasal, and rectal applications using a whole-body population-based PBPK simulator, Simcyp ${ }^{\circledR}$. The model evaluation was carried out using visual predictive checks, observed/predicted ratios $\left(\mathrm{R}_{\mathrm{obs} / \mathrm{pred}}\right)$, and the average fold error (AFE) of PK parameters. The Diazepam PBPK model successfully predicted diazepam PK in an adult population after doses were administered through IV, oral, intranasal, and rectal routes, as the $\mathrm{R}_{\mathrm{obs} / \mathrm{pred}}$ of all PK parameters were within a two-fold error range. The developed model can be used for the development and optimization of novel diazepam dosage forms, and it can be extended to simulate drug response in situations where no clinical data are available (healthy and disease).
\end{abstract}

Keywords: physiologically based pharmacokinetic (PBPK); Simcyp ${ }^{\circledR}$; diazepam; intranasal; rectal; route of administration; pharmacokinetics

\section{Introduction}

The amnesic and anxiolytic properties of benzodiazepines make this pharmacological class clinically useful in several indications, including insomnia, anxiety, muscle relaxation, and epilepsy, but their use is also associated with several unwanted side effects [1,2]. Among the benzodiazepines, diazepam is the most commonly prescribed medium potency long-acting drug [3,4]. Diazepam is uniquely metabolized in the liver into a pharmacologically active metabolite, $\mathrm{N}$-desmethyldiazepam, by demethylation and hydroxylation $[2,5,6]$. Diazepam shows wide interindividual variability in its metabolism, which results in marked differences in its systemic concentrations. Moreover, the genetic variability in the 
expressions of CYP2C19 and CYP3A4 can affect its therapeutic efficacy and may lead to adverse drug reactions [7-10].

Diazepam is commonly employed as an anxiolytic and anticonvulsant in intravenous (IV), oral, intramuscular, intranasal, and rectal dosage forms [3,4]. It is administered through different routes of drug administration for the management of acute and chronic diseases [11]. Parenteral diazepam is preferred in hospitals because of its rapid action (especially to suppress seizures), but this route of administration is not convenient in ambulatory settings and is also associated with serious side effects, i.e., hypotension, dysrhythmias, etc. $[12,13]$. The other routes of administration, i.e., oral, intranasal, and rectal are considered more valuable when the IV route becomes inconvenient. Diazepam's high permeability leads to rapid drug absorption via the rectal route, and diazepam is the only approved drug by U.S Food and Drug Administration (FDA) for rectal administration for out-patient treatment of early status epilepticus specifically in pediatrics [14-16]. On the other hand, the intranasal passage is an alternative to the oral and rectal route for diazepam administration for treating acute seizure management $[17,18]$. For any treatment, the therapeutic goal is only achieved if the drug is effective through the specified route of administration without causing any harm. To facilitate the clinical use of diazepam, there is a need to develop other non-oral formulations for humans when the oral route of administration is not convenient such as transdermal applications. Although such formulations have been examined and assessed in animals, they have not yet been tested in humans [19-21]. The development of non-oral dosage forms in humans can be facilitated by utilizing Physiologically Based Pharmacokinetics (PBPK), which presents countless opportunities for improvement in drug development in healthy and diseased populations [22].

PBPK models incorporate drug-dependent parameters along with the populationdependent system parameters in the presence of intrinsic or extrinsic factors to estimate the pharmacokinetics (PK) of the drug [23]. The concept of PBPK was established in 1937 [24], almost a decade ago, but for the last few years, PBPK modeling has been used as a tool for drug development and discovery, as described in several literature reviews [25-28]. PBPK models not only predict the clinical PK of a chemical entity but also reveal variables that may influence drug development, i.e., drug-drug interactions (DDI) or disease-states $[29,30]$. By allowing for the incorporation of in vitro drug release data, the PBPK modeling platforms [31,32] can be used to estimate the absorption, distribution, metabolism, and excretion (ADME) of the drug, which can assist in designing and optimizing novel dosage forms [33].

There are few published reports for the PBPK models for diazepam, which are focused on predicting its PK and DDIs in both humans and animals [34-36]. One study reported a PBPK model for diazepam to evaluate its DDIs with opioids (oxycodone, buprenorphine, and fentanyl) [35]. In contrast, another study aimed to develop a diazepam PBPK model by using different modeling and simulation tools after IV application only [34]. The third reported diazepam PBPK model was focused on the prediction of drug parameters in rats [36]. Since diazepam is administered through different routes of administration (IV, oral, intranasal, and rectal), if a PBPK model that can predict its PK after application of different dosage forms is developed, it may have many clinical applications. Keeping this in mind, a PBPK diazepam model was developed using a systematic model-building approach $[37,38]$ that was capable of predicting its ADME through different routes of drug administration. This study aims to develop a PBPK model in a healthy population for the prediction and evaluation of diazepam pharmacokinetics after the administration of the drug through different routes, i.e., IV, oral, intranasal, and rectal.

\section{Methods}

\subsection{Modeling Software}

Simcyp ${ }^{\circledR}$ version 19 release 1 (Simcyp Ltd., Sheffield, UK), a population-based simulator, was employed for diazepam PBPK model development. 


\subsection{Modeling Approach}

The process of PBPK model development commenced with the literature search for the extraction of drug-specific and population-specific parameters. The obtained data, i.e., molecular weight, fraction absorbed $\left(f_{a}\right)$, blood to plasma ratio (B:P), etc. were incorporated into the program to simulate and evaluate the IV profiles in the healthy adults. After the IV model was successfully developed in the adult population, oral PK profiles were simulated by incorporating oral drug absorption parameters, i.e., human jejunum permeability $\left(\mathrm{P}_{\text {eff }}\right)$, etc. After successful oral data assessment, the clinical PK profiles of other routes of administration for diazepam were evaluated, i.e., intranasal and rectal. The layout for the developed diazepam PBPK model is given in Figure 1.

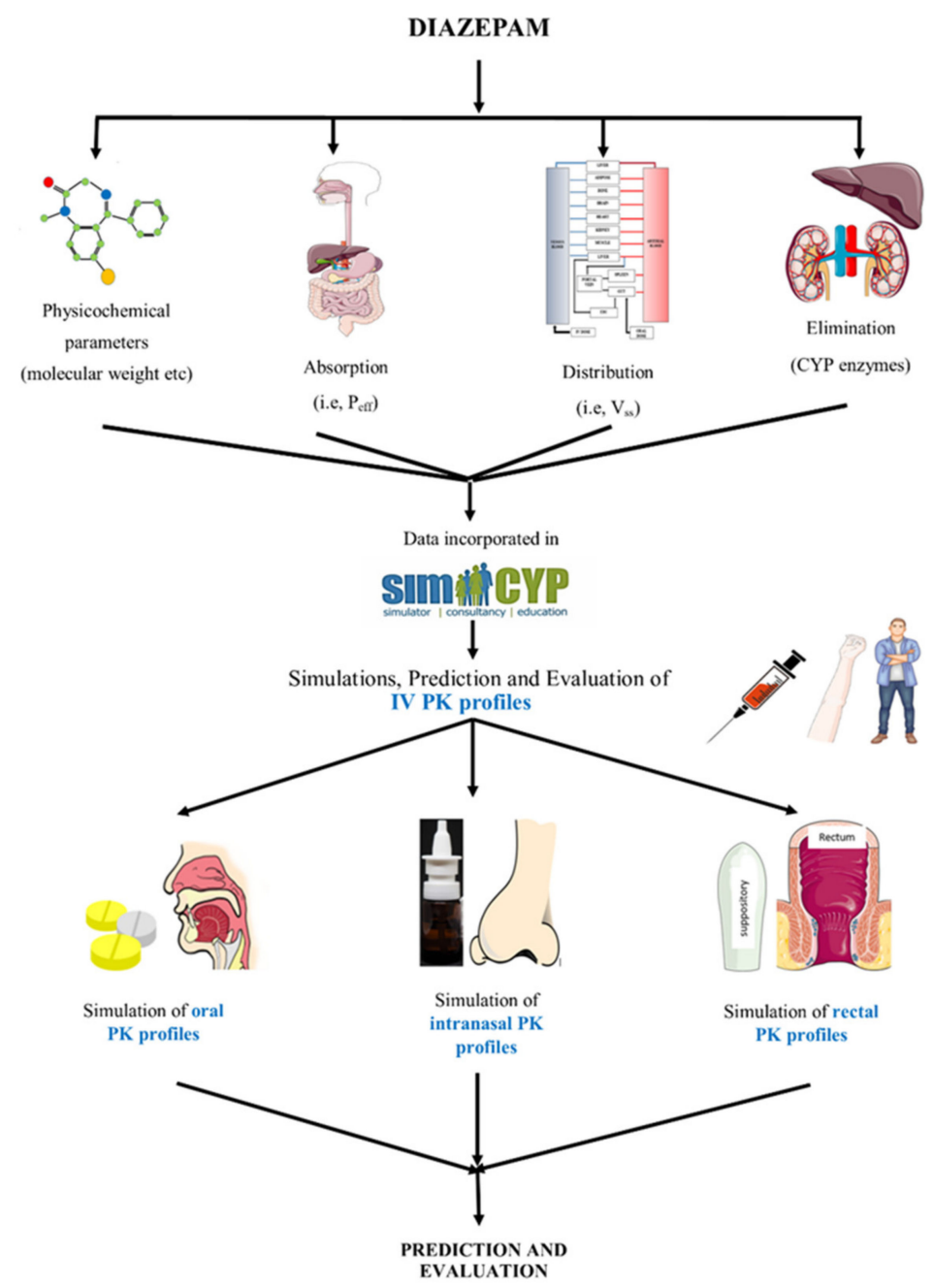

Figure 1. Systematic diagram for the development of the PBPK model of diazepam. Human jejunum permeability $\left(\mathrm{P}_{\text {eff }}\right)$, the volume of distribution at steady-state $\left(\mathrm{V}_{\mathrm{ss}}\right)$, pharmacokinetic $(\mathrm{PK})$, and intravenous (IV). The figure was produced using "Servier Medical Art" (https: / www.smart.servier. com, accessed on 12 September 2021).

\subsection{Model Parameters}

The parameterization of the model began with a thorough review of the published literature, including in vitro and in vivo data for diazepam. The physicochemical properties of diazepam including molecular weight, octanol-water partition coefficient $\left(\log \mathrm{P}_{\mathrm{o}: \mathrm{w}}\right)$, and acid dissociation constant (pKa) are given in Table 1. For estimating drug absorption via oral, intranasal, and rectal routes, the advanced dissolution, absorption, and metabolism (ADAM) model was utilized. The $\mathrm{P}_{\text {eff }}$ was predicted using the number of hydrogen bond donors (HBD) and polar surface area (PSA). The predicted $P_{\text {eff }}$ value for diazepam was 
$12.434 \times 10^{-4} \mathrm{~cm} / \mathrm{s}$ by incorporating PSA and HBD values of $32.67 \mathrm{~A}^{\mathrm{o}}$ and 0 , respectively [39]. For the prediction of diazepam distribution in an adult population, a wholebody full PBPK model was applied for estimating the tissue-to-plasma partition co-efficient and volume of distribution at steady-state $\left(\mathrm{V}_{\mathrm{ss}}\right)$ using "Method-3" (The Rodger and Rowland method + ion membrane permeability) within the Simcyp ${ }^{\circledR}$. The Michaelis-Menten constant $\left(\mathrm{K}_{\mathrm{m}}\right)$ and maximum rate of reaction $\left(V_{\max }\right)$ for CYP2B6, CYP2C19, CYP3A4, and CYP3A5 were used for predicting drug clearance. The final diazepam-specific input parameters for the developed PBPK model are given in Table 1.

Table 1. Drug-specific input parameters of diazepam.

\begin{tabular}{|c|c|c|c|}
\hline Parameters & Value & & Ref. \\
\hline \multicolumn{4}{|c|}{ Physicochemical Properties } \\
\hline $\begin{array}{l}\text { Molecular Weight } \\
(\mathrm{g} / \mathrm{mol})\end{array}$ & \multicolumn{2}{|c|}{284.74} & {$[40]$} \\
\hline $\log P_{\mathrm{O}: \mathrm{w}}$ & \multicolumn{2}{|c|}{2.82} & [35] \\
\hline pKa & \multicolumn{2}{|l|}{3.4} & [41] \\
\hline \multicolumn{4}{|c|}{ Absorption } \\
\hline \multicolumn{4}{|l|}{ Model } \\
\hline $\mathrm{P}_{\mathrm{eff}, \mathrm{man}}(\mathrm{cm} / \mathrm{s})$ & \multicolumn{2}{|c|}{$12.434 \times 10^{-4 a, b}$} & [35] \\
\hline PSA $\left(\mathrm{A}^{\mathrm{O}}\right)$ & \multicolumn{2}{|c|}{32.67} & [39] \\
\hline HBD & \multicolumn{2}{|l|}{0} & [39] \\
\hline \multicolumn{4}{|c|}{ Distribution } \\
\hline $\begin{array}{c}\text { Model Prediction } \\
\text { Method }\end{array}$ & \multicolumn{3}{|c|}{ The Rodger and Rowland Method + Ion Membrane Permeability } \\
\hline $\mathrm{B} / \mathrm{P}$ ratio & \multicolumn{2}{|c|}{0.58} & [41] \\
\hline $\mathrm{f}_{\mathrm{u}}$ & \multicolumn{2}{|c|}{0.03} & {$[3,42]$} \\
\hline $\mathrm{V}_{\mathrm{ss}}(\mathrm{L} / \mathrm{kg})$ & \multicolumn{2}{|c|}{$0.66^{\mathrm{a}, \mathrm{c}}$} & {$[35,43]$} \\
\hline \multicolumn{4}{|c|}{ For Intranasal Administration } \\
\hline Lung $f_{a}$ & \multicolumn{2}{|c|}{$0.7^{\mathrm{d}}$} & \\
\hline Lung $\mathrm{k}_{\mathrm{a}}$ & \multicolumn{2}{|c|}{$1.6^{\mathrm{d}, \mathrm{e}}$} & \\
\hline \multicolumn{4}{|c|}{ Elimination } \\
\hline $\mathrm{f}_{\text {umic }}$ & \multicolumn{2}{|c|}{$0.59^{a}$} & \\
\hline N-demethylation & $V_{\max }(\mathrm{pmol} / \mathrm{min} / \mathrm{pmol})$ & $\mathbf{K}_{\mathbf{m}}(\mu \mathrm{M})$ & \\
\hline CYP2B6 & 3.6 & 113 & \multirow{4}{*}{ [44] } \\
\hline CYP2C19 & 2.3 & 32 & \\
\hline CYP3A4 & 14.8 & 1828 & \\
\hline CYP3A5 & 1.8 & 293 & \\
\hline \multicolumn{4}{|c|}{ 3-hydroxylation } \\
\hline CYP2B6 & 0.1 & 150 & \multirow{4}{*}[44]{} \\
\hline CYP2C19 & 20.2 & 846 & \\
\hline CYP3A4 & 151.3 & 2235 & \\
\hline CYP3A5 & 48.4 & 316 & \\
\hline
\end{tabular}

$\overline{{ }^{a}}$ Value predicted by Simcyp, ${ }^{\mathrm{b}}$ reported value, ${ }^{\mathrm{c}}$ the reported value range was $0.59-1 \mathrm{~L} / \mathrm{kg},{ }^{\mathrm{d}}$ adjusted by manual optimization, ${ }^{\mathrm{e}}$ adjusted to 3.2 while simulating supersaturated solution, blood-to-plasma ratio (B:P), fraction unbound $\left(\mathrm{f}_{\mathrm{u}}\right)$, Michaelis-Menten constant $\left(\mathrm{K}_{\mathrm{m}}\right)$, maximum rate of metabolic formation $\left(V_{\max }\right)$, the volume of distribution at steady-state $\left(\mathrm{V}_{\mathrm{ss}}\right)$, human jejunum permeability $\left(\mathrm{P}_{\text {eff }}\right)$, polar surface area (PSA), hydrogen bonding donor $(\mathrm{HBD})$, acid dissociation constant $(\mathrm{pKa})$, octanol-water partition coefficient $\left(\log \mathrm{P}_{\mathrm{o}: \mathrm{w}}\right)$, fraction absorbed $\left(\mathrm{f}_{\mathrm{a}}\right)$, and absorption rate constant $\left(\mathrm{k}_{\mathrm{a}}\right)$.

\subsection{Pharmacokinetic Data}

A detailed online literature search was executed to categorize the PK profiles (plasma concentration vs. time profiles or data) of diazepam in the adult population for model development. The studies were selected based on the PK profiles, the route of adminis- 
tration (IV, oral, intranasal, and rectal), the dose administered, age, the female proportion, and the duration of the study. The observed data were extracted by scanning PK profiles through GetData Graph Digitizer V.2.26.0 (http:/ / getdata-graph-digitizer.com, accessed on 12 September 2021) [45].

In conclusion, 8 clinical studies and 20 concentrations vs. time profiles were added for diazepam model development; out of these 20 profiles, 6 were based on IV administration (71 individuals), 5 were profiles of oral (88 individuals), 6 were of intranasal administration (66 individuals), and 3 were of rectal diazepam administration (38 individuals) were used. Among all of these PK profiles, about one-third (two IV, two oral, two intranasal, and one rectal) were employed for diazepam PBPK model development and the remaining two-third (four IV, three oral, four intranasal, and two rectal) were utilized for verification of the model. For model evaluation, all of the observed clinical PK data were used. Table 2 shows the demographic data utilized for diazepam model construction and evaluation in the adult populations.

Table 2. Population data for IV, oral, intranasal, and rectal administration of diazepam in the adult population.

\begin{tabular}{|c|c|c|c|c|c|c|c|c|}
\hline No. & Population & $\begin{array}{c}\text { No. of } \\
\text { Subjects }\end{array}$ & $\begin{array}{l}\text { Dose } \\
(\mathrm{mg})\end{array}$ & Dosage Form & Age (Years) & $\begin{array}{l}\text { Weight } \\
\text { (kg) }\end{array}$ & $\begin{array}{c}\text { Female } \\
\text { Proportion }\end{array}$ & Ref. \\
\hline \multicolumn{9}{|c|}{ IV } \\
\hline 1 & Healthy & 9 & 2 & IV solution & $20-30$ & $58-80$ & 0 & [46] \\
\hline 2 & Healthy & 8 & 5 & IV solution & Mean 28.3 & - & 0.33 & [47] \\
\hline 3 & Healthy & 24 & 5 & IV solution & $18-45$ & Mean 71.8 & 0.2 & [48] \\
\hline 4 & Healthy & 20 & 7.5 & IV solution & Mean 28.8 & Mean 72.6 & 0 & [49] \\
\hline 5 & Healthy & 9 & 1 & IV solution & $18-25$ & $58-70$ & 0.33 & [15] \\
\hline 6 & Healthy & 1 & 10 & $\begin{array}{c}\text { IV solution } \\
\text { Oral }\end{array}$ & $26-37$ & $60-85$ & 0.2 & [50] \\
\hline 7 & Healthy & 11 & 2 & - & $19-35$ & - & 0.27 & [51] \\
\hline 8 & Healthy & 11 & 5 & - & $19-35$ & - & 0.27 & [51] \\
\hline 9 & Healthy & 48 & 10 & Tablets & $18-44$ & $59.1-95$ & 0 & [52] \\
\hline 10 & Healthy & 11 & 10 & - & $19-35$ & - & 0.27 & [51] \\
\hline 11 & Healthy & 9 & 10 & $\begin{array}{l}\text { Tablet } \\
\text { Intranasal }\end{array}$ & $18-25$ & $58-70$ & 0.33 & [15] \\
\hline 12 & Healthy & 9 & 2 & Solution & $20-30$ & $58-80$ & 0 & [46] \\
\hline 13 & Healthy & 8 & 5 & Supersaturated solution & Mean 28.3 & - & 0.33 & [47] \\
\hline 14 & Healthy & 24 & 10 & Solution & $18-45$ & Mean 71.8 & 0.2 & [48] \\
\hline 15 & Healthy & 24 & 10 & Suspension & $18-45$ & Mean 71.8 & 0.2 & [48] \\
\hline 16 & Healthy & 8 & 10 & Supersaturated solution & Mean 28.3 & - & 0.33 & [47] \\
\hline 17 & Healthy & 1 & 10 & $\begin{array}{l}\text { Solution } \\
\text { Rectal }\end{array}$ & $26-37$ & $60-85$ & 0.2 & [50] \\
\hline 18 & Healthy & 9 & 10 & Solution & $18-25$ & $58-70$ & 0.33 & [15] \\
\hline 19 & Healthy & 9 & 10 & Suppository & $18-25$ & $58-70$ & 0.33 & [15] \\
\hline 19 & Healthy & 20 & 15 & Gel & Mean 28.8 & Mean 173.9 & 0 & [49] \\
\hline
\end{tabular}

\subsection{Model Evaluation}

For every PK profile, 100 individuals were selected as a virtual population to perform a simulation by incorporating the parameters, i.e., the administration route, age range, female proportion, dosing, and study duration, as mentioned in the above-published studies. The evaluation of the developed diazepam PBPK model was initially performed with visual predictive checks by overlaying mean observed PK profiles on predicted data, which include the mean, 5th percentile and 95th percentile, and maximum and minimum predicted values. A non-compartmental analysis (NCA) was performed for the comparison of observed and predicted values of PK parameters including clearance (CL), area under the plasma concentration vs. time curve $\left(\mathrm{AUC}_{0-\mathrm{t}}\right)$, and maximum plasma concentration $\left(\mathrm{C}_{\max }\right)$ values. Moreover, the fold-error (observed/predicted ratios) and average fold error (AFE) of $\mathrm{AUC}_{0-\mathrm{t}}, \mathrm{C}_{\max }$, and CL were calculated using Equations (1) and (2). A two-fold error range (within 0.5-2-fold range) was used for the evaluating ratios ( $\left.\mathrm{R}_{\mathrm{obs} / \mathrm{pred}}\right)$ for PK parameters [53].

Mean observed/predicted ratio

$$
\text { ratio }_{\left(\frac{\mathrm{obs}}{\mathrm{pred}}\right)}=\frac{\text { observed value of PK parameter }}{\text { predicted value of PK parameter }}
$$


Average fold error

$$
\mathrm{AFE}=10 \frac{\sum \log \text { (fold error) }}{\mathrm{N}}
$$

Additionally, the values of bioavailability parameters such as $F_{a}$ (fraction of oral dose absorbed from the intestinal lumen), $\mathrm{F}_{\mathrm{g}}$ (fraction of drug that escaped both intestinal firstpass metabolism and transporter-secretion available at hepatic portal blood), $\mathrm{F}_{\mathrm{h}}$ (fraction of drug escaping hepatic first-pass elimination) were predicted after simulating oral and intranasal profiles. Through these parameters, the oral and intranasal data can be evaluated using predicted bioavailability, which can be calculated using the following equation:

$$
\mathrm{F}=\mathrm{F}_{\mathrm{a}} \cdot \mathrm{F}_{\mathrm{g}} \cdot \mathrm{F}_{\mathrm{h}}
$$

\section{Results}

\subsection{Intravenous Dose Administration in the Adult Population}

The observed and predicted systemic diazepam concentration profiles can be seen in Figure 2 . The visual predictive checks showed that the developed model successfully predicted diazepam PK after its IV administration within the dose range of 2-10 mg. The mean $\mathrm{AUC}_{0-\mathrm{t}}$ and $\mathrm{C}_{\max } \mathrm{R}_{\mathrm{obs} / \text { pred }}$ were 0.94 (95\% CI 0.75-1.13) and 0.95 (95\% CI 0.82-1.08), respectively. All of the PK parameters were within the two-fold error range (Tables 3 and 4, Figure 3).

\begin{tabular}{|c|c|c|c|c|c|c|c|c|c|c|c|}
\hline & \multirow[t]{2}{*}{ Dose (mg) } & \multicolumn{2}{|c|}{$\mathrm{C}_{\max }(\mathrm{ng} / \mathrm{mL})$} & \multirow[t]{2}{*}{ Ratio } & \multicolumn{2}{|c|}{$\mathrm{AUC}_{0-\mathrm{t}}(\mathrm{ng} . \mathrm{h} / \mathrm{mL})$} & Ratio & \multicolumn{2}{|c|}{ CL (L/h) } & \multirow[t]{2}{*}{ Ratio } & \multirow[t]{2}{*}{ Ref. } \\
\hline & & \multicolumn{2}{|c|}{ Observed Predicted } & & \multicolumn{2}{|c|}{ Observed Predicted } & & \multicolumn{2}{|c|}{ Observed Predicted } & & \\
\hline \multicolumn{12}{|c|}{ IV } \\
\hline 1 & 2 & 157.06 & 154.39 & 1.01 & 285.45 & 256.60 & 1.11 & 7.00 & 7.79 & 0.89 & [46] \\
\hline 2 & 5 & 332.28 & 452.92 & 0.73 & 455.11 & 522.20 & 0.87 & 10.98 & 9.57 & 1.14 & [47] \\
\hline 3 & 5 & 492.1 & 479.77 & 1.02 & 851.74 & 1305.30 & 0.65 & 5.87 & 3.83 & 1.53 & [48] \\
\hline 4 & 7.5 & 536.44 & 605.14 & 0.88 & 1244 & 1428.08 & 0.87 & 6.27 & 5.46 & 1.14 & [49] \\
\hline 5 & 10 & 623 & 586.11 & 1.06 & 3505.37 & 3117.92 & 1.12 & 2.85 & 3.2 & 0.89 & [15] \\
\hline 6 & 10 & 642.95 & 634.13 & 1.01 & 4491.90 & 4364.79 & 1.02 & 2.22 & 2.29 & 0.97 & [50] \\
\hline \multicolumn{12}{|c|}{ Oral } \\
\hline 1 & 2 & 62.07 & 63.97 & 0.97 & 330 & 406.55 & 0.81 & 6.06 & 4.91 & 1.23 & [51] \\
\hline 2 & 5 & 125.24 & 159.95 & 0.78 & 784.19 & 1012.40 & 0.77 & 6.37 & 4.93 & 1.29 & [51] \\
\hline 3 & 10 & 325 & 311.87 & 1.04 & 3487 & 2965.75 & 1.17 & 2.86 & 3.37 & 0.80 & [15] \\
\hline 4 & 10 & 255.53 & 322.62 & 0.80 & 1540.28 & 2026.76 & 0.75 & 6.49 & 4.93 & 1.31 & [51] \\
\hline 5 & 10 & 352 & 318.99 & 1.10 & 1445.96 & 1493.59 & 0.96 & 6.91 & 6.66 & 1.03 & [52] \\
\hline \multicolumn{12}{|c|}{ Intranasal } \\
\hline 1 & 2 & 46.25 & 39.66 & 1.16 & 161.73 & 159.94 & 1.01 & 12.36 & 12.5 & 0.98 & [46] \\
\hline 2 & 5 & 102.66 & 127.34 & 0.80 & 309.82 & 352.62 & 0.87 & 16.13 & 14.18 & 1.13 & [47] \\
\hline 3 & 10 & 218.15 & 222.08 & 0.98 & 1513.78 & 1532.92 & 0.98 & 6.60 & 6.52 & 1.01 & [48] \\
\hline 4 & 10 & 172.99 & 222.48 & 0.77 & 1084 & 1523.59 & 0.70 & 9.22 & 6.56 & 1.41 & [48] \\
\hline 5 & 10 & 180.51 & 254.69 & 0.70 & 588.64 & 710.80 & 0.82 & 16.98 & 14.06 & 1.20 & [47] \\
\hline 6 & 10 & 236.82 & 222.70 & 1.06 & 3558.44 & 3033.84 & 1.17 & 2.81 & 3.29 & 0.85 & [50] \\
\hline \multicolumn{12}{|c|}{ Rectal } \\
\hline 1 & 10 & 297 & 224.17 & 1.32 & 3566.35 & 2699.95 & 1.32 & 2.80 & 3.70 & 0.75 & [15] \\
\hline 2 & 10 & 254 & 229.40 & 1.10 & 3258.12 & 2666.01 & 1.22 & 3.06 & 3.75 & 0.81 & [15] \\
\hline 3 & 15 & 384.86 & 350.74 & 1.09 & 2070.02 & 2028.11 & 1.02 & 7.24 & 7.39 & 0.97 & [49] \\
\hline
\end{tabular}

Table 3. Observed and predicted values of PK parameters after IV, oral, intranasal, and rectal routes of administration.

Table 4. $R_{\mathrm{obs} / \text { pred }}$ and AFE values of PK parameters in an adult population after IV, oral, intranasal, and rectal administration of diazepam.

\begin{tabular}{ccc}
\hline Parameters & $\mathbf{R}_{\text {obs/pred }}$ & AFE \\
\hline & IV & \\
$\mathrm{AUC}_{0-\mathrm{t}}$ & 0.94 & 0.93 \\
$\mathrm{CL}$ & 1.10 & 1.08 \\
$\mathrm{C}_{\max }$ & 0.96 & 0.95 \\
\hline
\end{tabular}


Table 4. Cont.

\begin{tabular}{ccc}
\hline Parameters & $\mathbf{R}_{\text {obs/pred }}$ & AFE \\
\hline & Oral & \\
$\mathrm{AUC}_{0-\mathrm{t}}$ & 0.90 & 0.89 \\
$\mathrm{CL}$ & 1.15 & 1.13 \\
$\mathrm{C}_{\max }$ & 0.94 & 0.93 \\
& Intranasal & \\
$\mathrm{AUC}_{0-\mathrm{t}}$ & 0.93 & 0.92 \\
$\mathrm{CL}$ & 1.10 & 1.09 \\
$\mathrm{C}_{\max }$ & 0.92 & 0.90 \\
& Rectal & 1.18 \\
$\mathrm{AUC}_{0-\mathrm{t}}$ & 1.19 & 0.85 \\
$\mathrm{CL}$ & 0.85 & 1.17 \\
$\mathrm{C}_{\max }$ & 1.18 &
\end{tabular}

(A) $2 \mathrm{mg}$

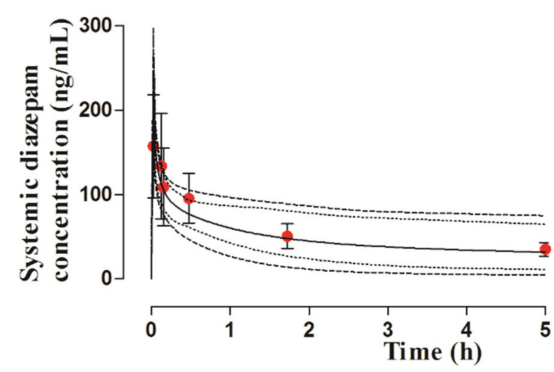

(C) $5 \mathrm{mg}$

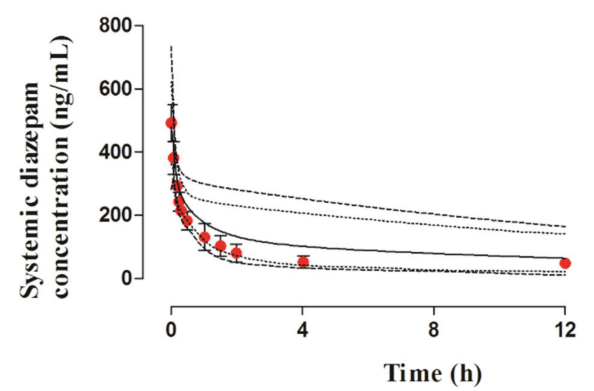

(E) $10 \mathrm{mg}$

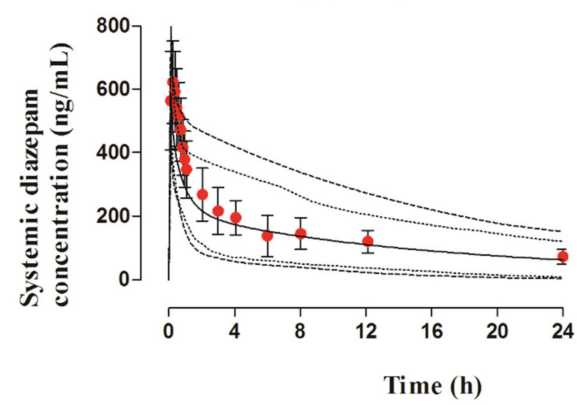

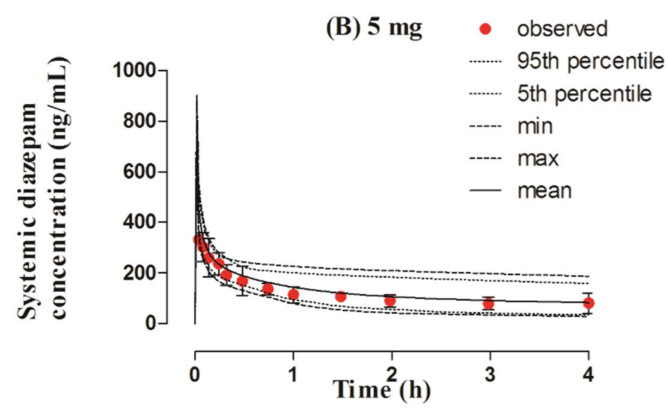

(D) $7.5 \mathrm{mg}$

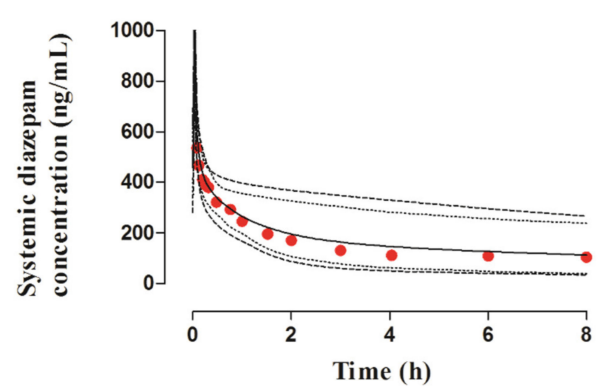

(F) $10 \mathrm{mg}$

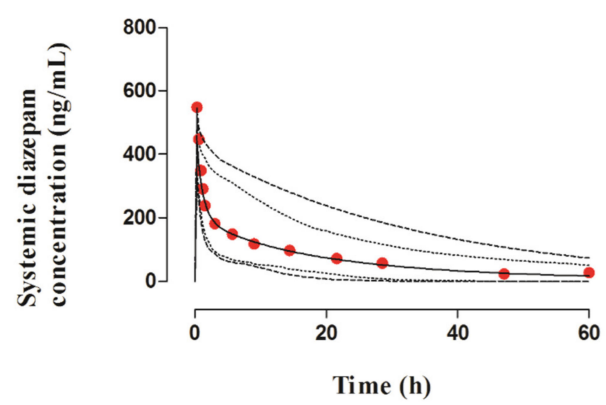

Figure 2. Observed and predicted systemic concentration profiles of diazepam after IV application. The solid line (-) represents the mean value; the dotted lines (...) indicate the 5th and 95th percentiles; the dash line (---) shows the maximum and minimum predicted values; and the red filled circles $(\bullet)$ represent the mean observed data along with the standard deviation, where available. The figure contains systemic diazepam concentration profiles after administering IV doses of (A) $2 \mathrm{mg}$ [46], (B) $5 \mathrm{mg}$ [47], (C) $5 \mathrm{mg}$ [48], (D) $7.5 \mathrm{mg}$ [49], (E) $10 \mathrm{mg}$ [15], and (F) $10 \mathrm{mg}$ [50]. 
(A) Area under the curve ( $\mathrm{AUC}_{0-\mathrm{t}}$ )

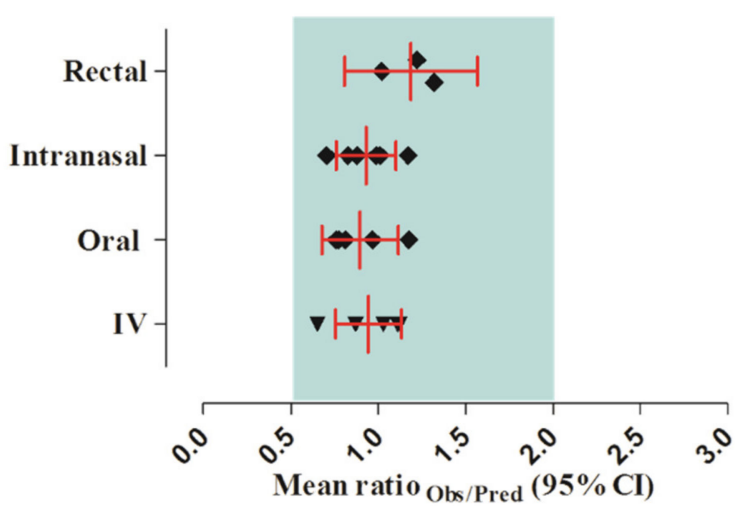

(B) Maximum systemic concentration $\left(\mathrm{C}_{\text {max }}\right)$

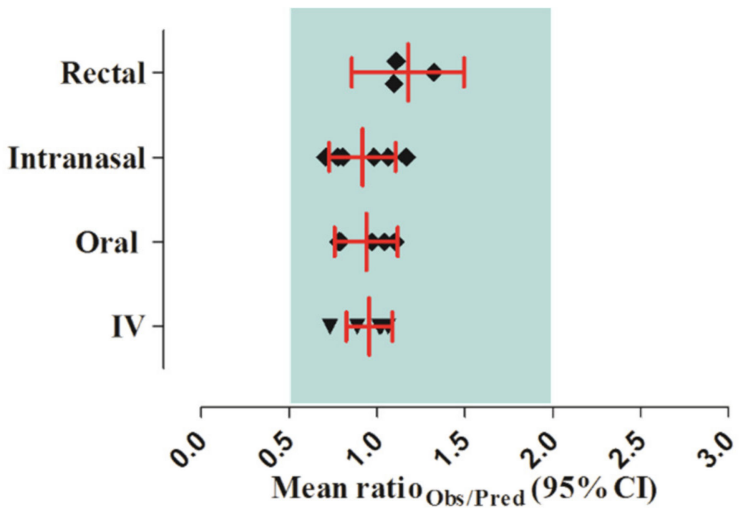

(C) Clearance

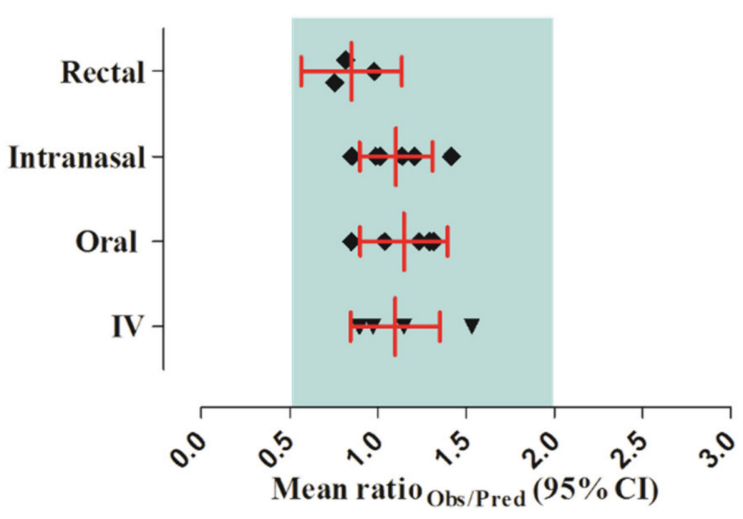

Figure 3. Mean ratio observed/predicted for the pharmacokinetic parameters of diazepam along with their $95 \%$ confidence intervals after IV, oral, intranasal, and rectal application. (A) Area under the curve $\left(\mathrm{AUC}_{0-1}\right),(\mathrm{B})$ maximum systemic concentration $\left(\mathrm{C}_{\max }\right),(\mathrm{C})$ clearance.

\subsection{Oral Dose Administration in the Adult Population}

The observed and predicted concentration profiles after the oral administration of a 2-10 mg dose of diazepam are given in Figure 4. The observed clinical data was in between the maximum and minimum values, as perceived by visual predictive checks. The mean $R_{\text {obs/pred }}$ of $C_{\max }$ and $C L$ were within the range of the two-fold error, as shown by the values of 0.93 (95\% CI 0.75-1.11) and 1.14 (95\% CI 0.90-1.39), respectively (Tables 3 and 4, and Figure 3). 
(A) $2 \mathrm{mg}$

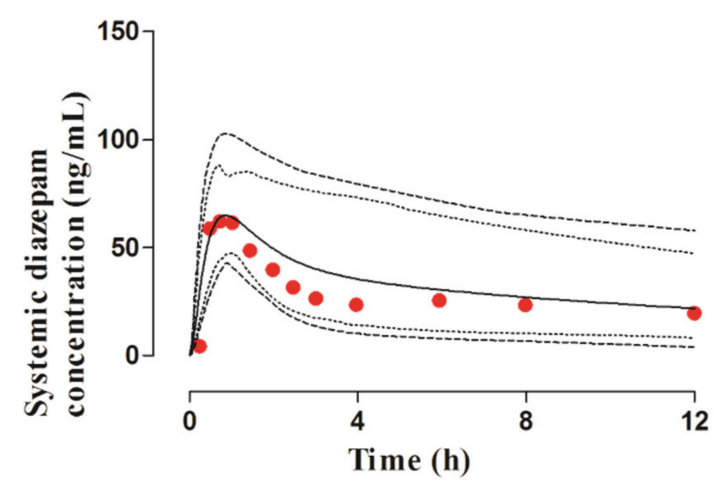

(C) $10 \mathrm{mg}$

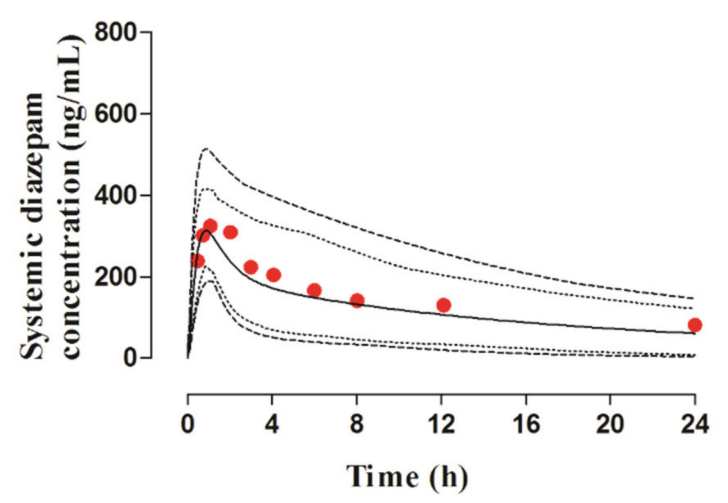

(E) $10 \mathrm{mg}$

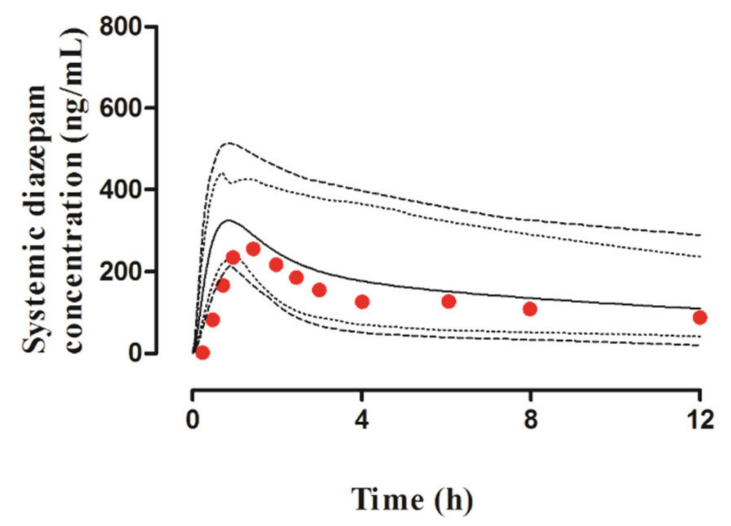

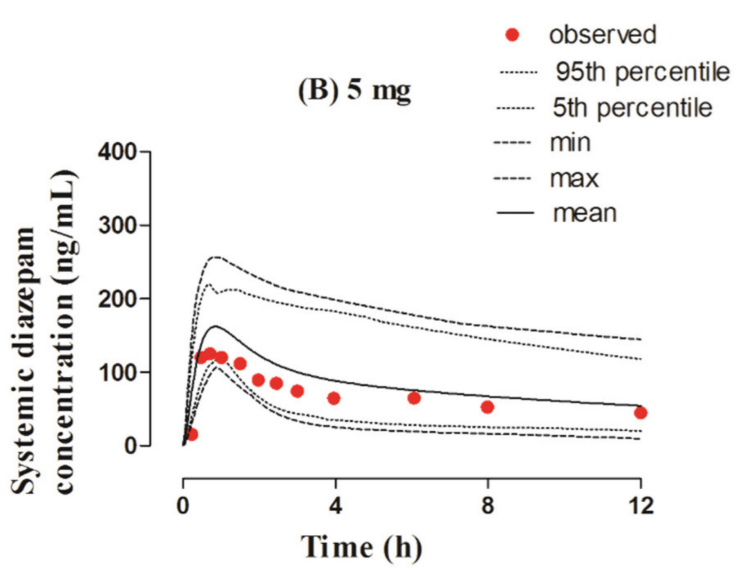

(D) $10 \mathrm{mg}$

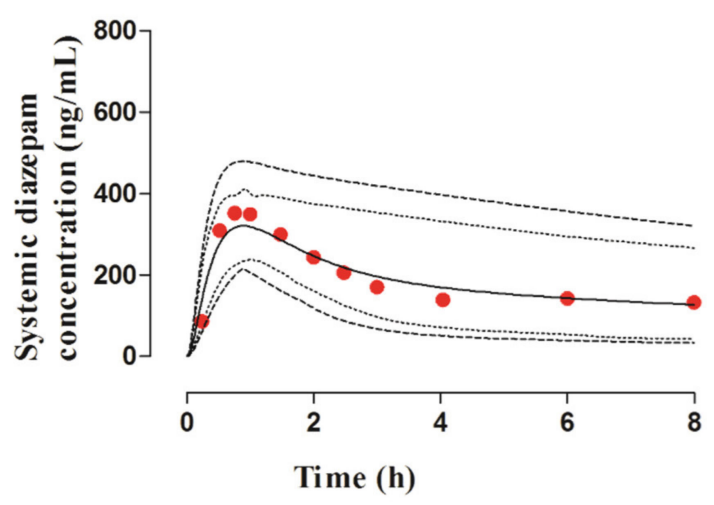

Figure 4. Observed and predicted systemic concentration profiles of diazepam after oral application. The solid line (-) represents the mean value, the dotted lines (...) indicate the 5th and 95th percentiles, the dash line (---) shows the maximum and minimum predicted values, and the red filled circles $(\bullet)$ represent the mean observed data. The figure contains systemic diazepam concentration profiles after administering oral doses of (A) $2 \mathrm{mg}$ [51], (B) $5 \mathrm{mg}$ [51], (C) $10 \mathrm{mg}$ [15], (D) $10 \mathrm{mg}$ [52], and (E) $10 \mathrm{mg}$ [51].

\subsection{Intranasal Dose Administered in the Adult Population}

The developed model effectively predicts diazepam concentration-time profiles after administration of the intranasal dose of $2-10 \mathrm{mg}$ in adult individuals, as shown in Figure 5 . The visual predictive checks represented that these predictions were in accordance with the observed data. Additionally, the PK parameters depicted the values within a two-fold range (0.5-2.0); the mean $\mathrm{R}_{\mathrm{obs} / \text { pred }}$ of $A U C_{0-\mathrm{t}}$ was 0.93 (95\% CI 0.76-1.10) and the $\mathrm{C}_{\max }$ value was 0.91 (95\% CI 0.72-1.10), which can be seen in Tables 3 and 4, and Figure 3. 
(A) $2 \mathrm{mg}$

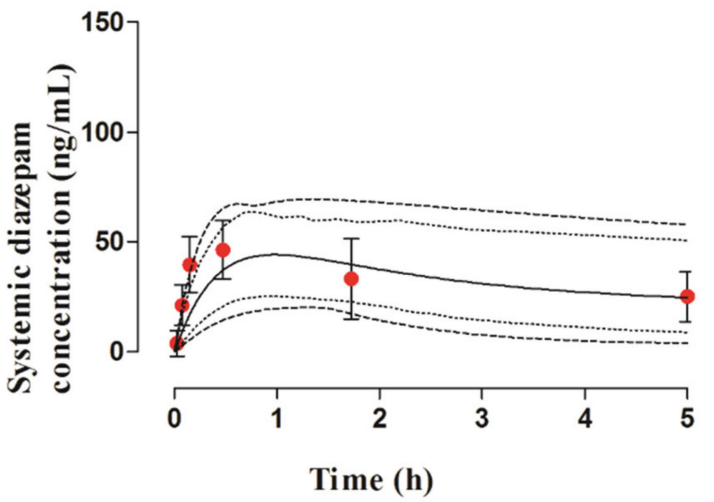

(C) $10 \mathrm{mg}$

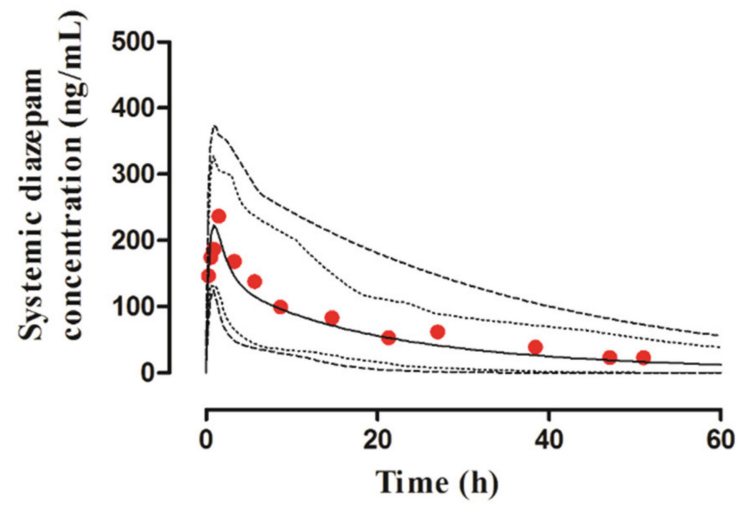

(E) $10 \mathrm{mg}$

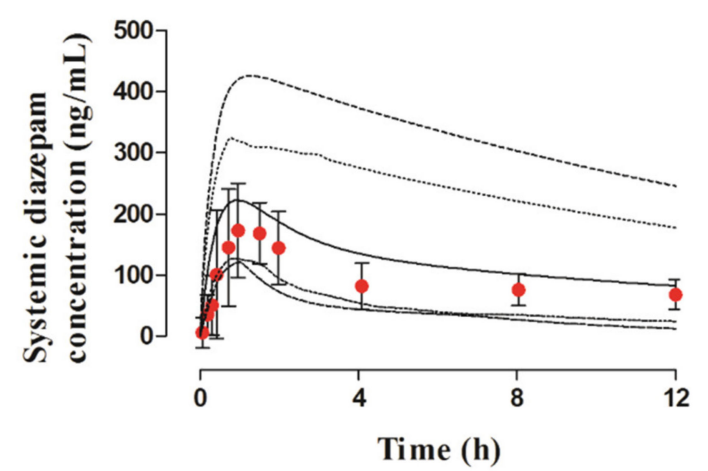

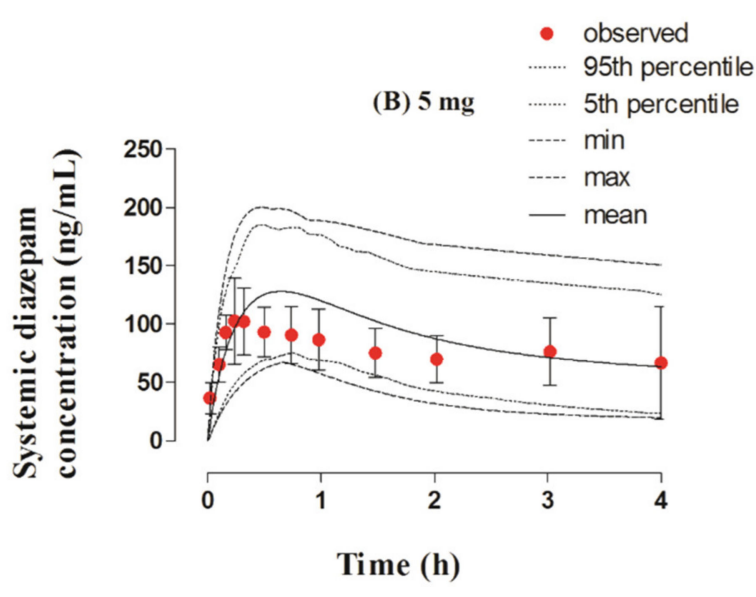

(D) $10 \mathrm{mg}$

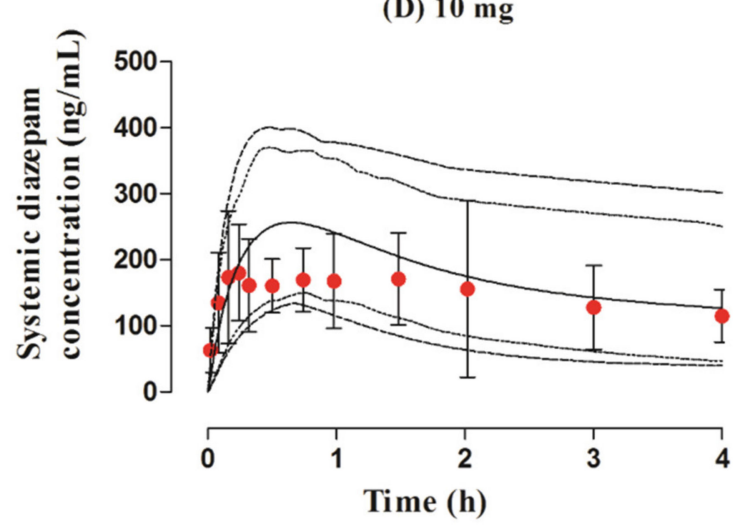

(F) $10 \mathrm{mg}$

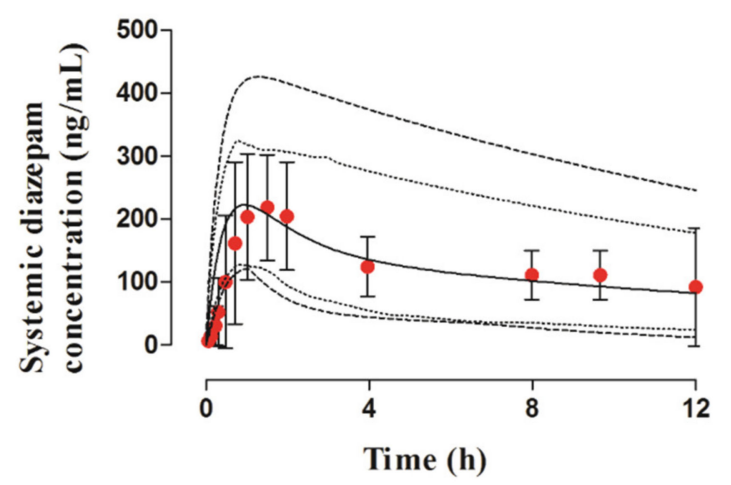

Figure 5. Observed and predicted systemic concentration profiles of diazepam after intranasal application. The solid line (-) represents the mean value; the dotted lines (....) indicate the 5 th and 95 th percentiles; the dash line (---) shows the maximum and minimum predicted values; and the red filled circles $(\bullet)$ represent the mean observed data along with the standard deviation, where available. The figure contains systemic diazepam concentration profiles after administering intranasal doses of (A) $2 \mathrm{mg}$ [46], (B) $5 \mathrm{mg}$ [47], (C) $10 \mathrm{mg}$ [50], (D) $10 \mathrm{mg}$ [47], (E) $10 \mathrm{mg}$ [48], and (F) $10 \mathrm{mg}$ [48].

\subsection{Rectal Dose Administered in the Adult Population}

The predicted diazepam concentration-time profiles after rectal administration doses of 10-15 mg were in complete agreement with the observed PK data (Figure 6). These results were further confirmed by the mean $R_{\mathrm{obs} / \text { pred }}$ of the PK parameters of diazepam being within the two-fold error range (Tables 3 and 4, and Figure 3 ) as $\mathrm{AUC}_{0-\mathrm{t}}$ after the rectal application was 1.18 (95\% CI 0.80-1.56). Additionally, the AFE values represented that the model effectively predicted PK parameters after rectal administration. 


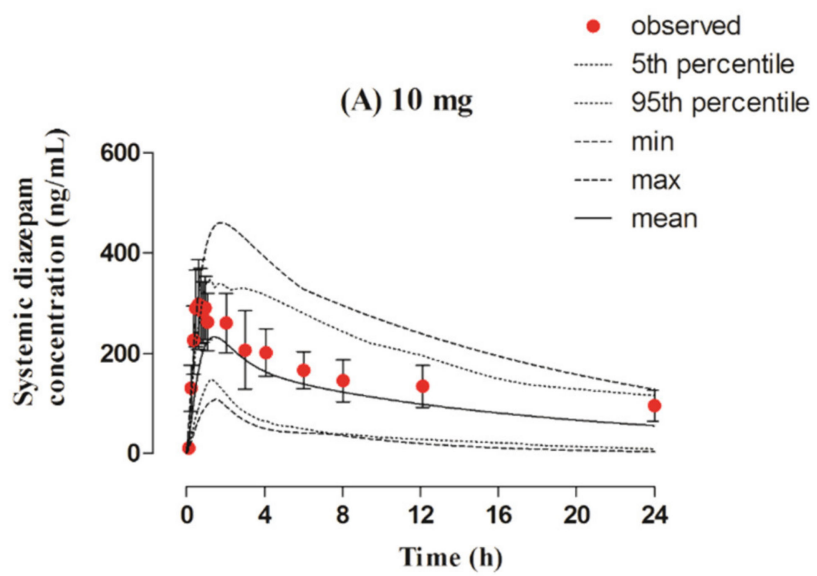

(B) $10 \mathrm{mg}$

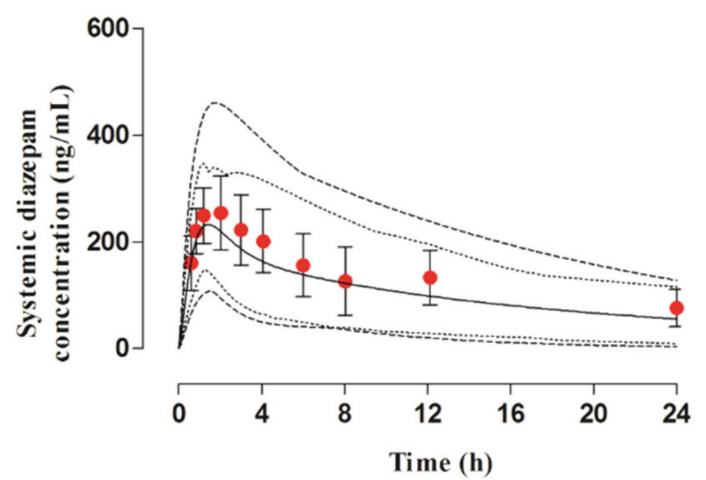

(C) $15 \mathrm{mg}$

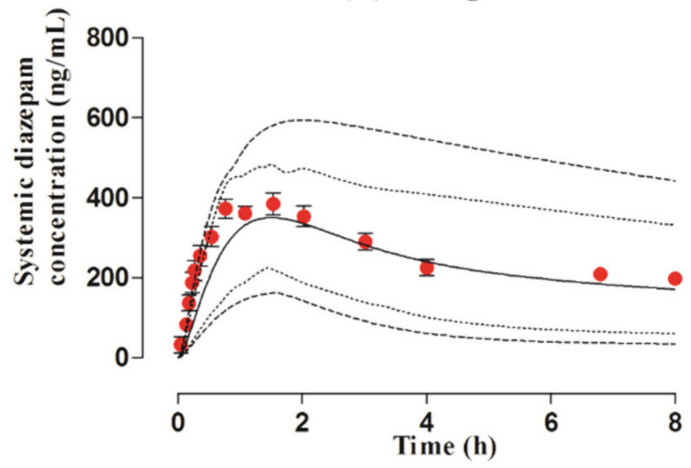

Figure 6. Observed and predicted systemic concentration profiles of diazepam after rectal application. The solid line (-) represents the mean value; the dotted lines (...) indicate the 5th and 95th percentiles; the dash line (---) shows the maximum and minimum predicted values; and the red filled circles $(\bullet)$ represent the mean observed data along with the standard deviation, where available. The figure contains systemic diazepam concentration profiles after administering rectal doses of (A) $10 \mathrm{mg}$ [15] (B) $10 \mathrm{mg}$ [15], and (C) $15 \mathrm{mg}$ [49].

\section{Discussion}

In the presented work, a PBPK model was developed to predict the ADME of diazepam after IV, oral, intranasal, and rectal administration. The systematic model building was commenced by predicting IV clinical profiles in adults by incorporating all drug and population-specific parameters in Simcyp ${ }^{\circledR}$. After successful evaluation of IV profiles, absorption parameters were incorporated for the prediction and evaluation of oral PK clinical data. Intranasal and rectal PK profiles were also evaluated in the same way as IV and oral data. 
The developed diazepam PBPK model represented comparable drug disposition in adults after IV administration as the mean $\mathrm{R}_{\mathrm{obs}}$ /pred value of $\mathrm{AUC}_{0-\mathrm{t}}$ with $95 \% \mathrm{CI}$ was 0.94 (95\% CI 0.75-1.13). Although diazepam is used as a first-line agent in the emergency management of seizures, it is difficult to administer IV diazepam to stop seizures in an ambulatory setup. The suitable diazepam alternatives in the outpatient setting are non-IV formulations.

The presented model successfully simulated oral diazepam PK data, and the observed and predicted systemic concentrations were in close association with the reported data as the mean $\mathrm{R}_{\text {obs/pred }} \mathrm{C}_{\max }$ value with 95\% CI was 0.93 (95\% CI 0.75-1.11). Moreover, the predicted bioavailability after the oral application was in the range of $76-97 \%$, which is comparable with the reported value of $94 \%$ [54]. The oral route of administration is not feasible in suppressing seizures due to its late onset of action and congestion problems. Due to this reason, clinicians prefer other routes of administration, i.e., rectal and intranasal, for diazepam administration to suppress seizures using rapid diazepam action.

Apart from the IV and oral routes, the intranasal route of administration was used as an alternative for drug administration from the early 1980s [55]. The intranasal route is commonly employed because of its accessibility, its rapid action without first-pass metabolism, its patient conformity, and its noninvasiveness [56-58]. Diazepam is considered effective for intranasal administration due to its physicochemical properties and provides extended action compared with other benzodiazepines [59]. This intranasal route for diazepam is more attractive for the user compared with some other formulations, i.e., rectal [11]. For intranasal PK profiles of diazepam, the abovementioned strategy of IV and oral formulations were implemented with additional parameters, i.e., $\mathrm{f}_{\mathrm{a}}$ and $\mathrm{k}_{\mathrm{a}}$. The presented model includes multiple intranasal formulations, i.e., solution, suspension, and supersaturated solutions. The supersaturated solution of diazepam is expected to be rapidly absorbed across the nasal mucosa soon after administration, which leads to the shorter residence time of the drug at the absorption site along with nasal drainage, which contributes to a decrease amount of drug available for absorption over time $[60,61]$. Therefore, in the case of a supersaturated solution, compared with other intranasal formulations, $\mathrm{k}_{\mathrm{a}}$ changed to accommodate the increased drug absorption because of rapid permeation in a short time. The model effectively predicted the overall PK parameters as $R_{\text {obs/pred }}$ with a $95 \%$ CI of $\mathrm{AUC}_{0-\mathrm{t}}$ was calculated as 0.93 (95\% CI 0.76-1.10). Thus, a solution with a drug given through the intranasal route is absorbed more rapidly than suspension [62], but the developed model showed no significant increase in drug disposition as the $\mathrm{AUC}_{0-\mathrm{t}}$ of the intranasal solution (1532 ng.h/mL) was slightly higher than that of the intranasal suspension (1523 ng.h/mL). Furthermore, the reported bioavailability after intranasal administration was $97 \%$ [48,63], and the model predictions were in the range of $81-97 \%$.

The other non-oral route for diazepam administration that has rapid absorption and showed up to $80 \%$ to $90 \%$ bioavailability is the rectal route. The therapeutic concentration of diazepam after rectal administration was achieved within 5 to $10 \mathrm{~min}$, similar to that of IV administration. However, the use of a rectal formulation has social limitations in terms of patient conformity $[16,64,65]$. In the recent past, a diazepam gel for rectal administration was the only drug available with an immediate action for suppressing seizures in ambulatory settings [66]. The presented study, successfully predicted the PK profiles of different rectal formulations, i.e., suppository, solution, and gel, that can be recognized with comparable values of PK parameters. The mean $\mathrm{R}_{\mathrm{obs}}$ /pred with a $95 \% \mathrm{CI}$ of $\mathrm{CL}$ was calculated as 0.85 (95\% CI 0.56-1.13). The predicted $\mathrm{AUC}_{0-8}$ of the rectal gel $(2028.11 \mathrm{ng} . \mathrm{h} / \mathrm{mL})$ [49] was lower than that of the $\mathrm{AUC}_{0-24}$ of the suppositories (2666.01 ng.h/mL) [15]. Although IV diazepam is commonly used to suppress prolonged seizures, seizures need to be stopped immediately at home before hospitalization. Apart from the intranasal route of diazepam, its rectal dosage forms are commonly employed to control seizures, as the only FDAapproved diazepam rectal gel (Diastat ${ }^{\circledR}$, Bausch Health NJ, USA) is intended for use in pediatrics [67]. The developed PBPK model may be used to optimize the other non-oral 
formulations (transdermal) in humans by utilizing the in vitro data (dissolution data) of the drug using the already reported strategies [68].

Ideally, the treatment option should be chosen based on disease type, rapid onset of action, easy administration, and extended duration with minimal adverse effects [11]. In terms of route of administration, diazepam has various pros and cons, where IV administration has a swift onset of action, but at the same time, it is not convenient in the ambulatory setting, and on the other hand, the oral route has slow absorption and administration issues, i.e., swallowing in seizure [16]. Intranasal and rectal routes of administration also have unwanted effects, i.e., irritation at the site of administration, but they are commonly employed for treating seizures because of their rapid action and minimal side effects [11] The comparative evaluation of the intranasal and the rectal formulations suggests that intranasal dosage forms are associated with a high variability in drug exposure and they often require the optimization of spray devices [60].

The previously published PBPK models for diazepam were focused on predicting its PK and DDIs in both humans and animals [34-36]. One study has used two Bayesian software for the development of a PBPK model of diazepam after the administration of an IV infusion only. Both tools produced very good fits at the individual and population levels [34]. The other study reported the development of full and minimal PBPK models for the evaluation of DDIs between opioids (fentanyl, oxycodone, and buprenorphine) and benzodiazepines (alprazolam, diazepam, midazolam, and triazolam). Full PBPK models were applied to diazepam and all opioids, while minimal PBPK models were developed for all benzodiazepines except diazepam [35]. The third reported PBPK model accounted for the parameter variability and uncertainty in the presence of qualitative and semi-quantitative data. The two approaches for the incorporation of parameter variability and uncertainty used in the study included the fuzzy and Monte Carlo simulations [36]. However, to date, there is no report for a PBPK model for diazepam that has been developed and evaluated in the adult population after implementing a systematic model-building approach. This is the first report of a whole-body full PBPK model for diazepam that has successfully predicted its PK after IV, oral, intranasal, and rectal administration.

\section{Conclusions}

Our diazepam PBPK model successfully predicted diazepam PK in the adult population after doses administered through IV, oral, intranasal, and rectal routes. The non-oral routes for diazepam administration are preferred in an ambulatory setting, especially as the IV route in seizing patients is not convenient in an outpatient setting and as it may lead to adverse effects. The developed model can be used for the development and optimization of novel diazepam dosage forms, and it can be extended to simulate drug response in situations where no clinical data are available as in diseased states and special populations (pediatrics).

Author Contributions: Conceptualization, S.K., M.F.R., I.I., H.S. and F.A.; formal analysis, S.K., M.F.R., A.M., A.u.R., W.A. and T.A.; funding acquisition, Y.A.B.J. and F.A.; Investigation, S.K., M.F.R., A.M., A.u.R., T.A., Y.A.B.J. and F.A.; methodology, S.K., M.F.R., I.I., H.S. and W.A.; project administration, S.K., M.F.R., I.I., A.M., Y.A.B.J. and F.A.; validation, S.K., M.F.R., H.S., A.u.R., W.A. and T.A.; writing—original draft, S.K., M.F.R., A.M., A.u.R., W.A. and F.A.; writing-review and editing, S.K., M.F.R., I.I., H.S., T.A. and Y.A.B.J. All authors have read and agreed to the published version of the manuscript.

Funding: This research was funded by the Distinguished Scientist Fellowship program at King Saud University, Riyadh, Saudi Arabia, through research supporting project number (RSP-2021/131).

Institutional Review Board Statement: Not applicable.

Informed Consent Statement: Not applicable. 
Acknowledgments: The authors extend their appreciation to the Distinguished Scientist Fellowship program at King Saud University, Riyadh, Saudi Arabia, for funding this work through research supporting project number (RSP-2021/131).

Conflicts of Interest: The authors declare no conflict of interest.

\section{References}

1. Crestani, F.; Löw, K.; Keist, R.; Mandelli, M.-J.; Möhler, H.; Rudolph, U. Molecular targets for the myorelaxant action of diazepam. Mol. Pharmacol. 2001, 59, 442-445. [CrossRef]

2. Griffin, C.E.; Kaye, A.M.; Bueno, F.R.; Kaye, A.D. Benzodiazepine pharmacology and central nervous system-mediated effects. Ochsner J. 2013, 13, 214-223. [PubMed]

3. Mandelli, M.; Tognoni, G.; Garattini, S. Clinical pharmacokinetics of diazepam. Clin. Pharmacokinet. 1978, 3, 72-91. [CrossRef] [PubMed]

4. Manchikanti, L.; Christo, P.J.; Trescot, A.; Falco, F.J.E. Pain Medicine E Interventional Pain Management: A Comprehensive Review: Clinical Aspects; ASIPP Publishing: Paducah, KY, USA, 2011.

5. Andersson, T.; Miners, J.; Veronese, M.; Birkett, D. Diazepam metabolism by human liver microsomes is mediated by both S-mephenytoin hydroxylase and CYP3A isoforms. Br. J. Clin. Pharmacol. 1994, 38, 131-137. [CrossRef]

6. Kaplan, S.; Jack, M.; Alexander, K.; Weinfeld, R. Pharmacokinetic profile of diazepam in man following single intravenous and oral and chronic oral administrations. J. Pharm. Sci. 1973, 62, 1789-1796. [CrossRef]

7. Fukasawa, T.; Suzuki, A.; Otani, K. Effects of genetic polymorphism of cytochrome P450 enzymes on the pharmacokinetics of benzodiazepines. J. Clin. Pharm. Ther. 2007, 32, 333-341. [CrossRef]

8. Qin, X.P.; Xie, H.G.; Wang, W.; He, N.; Huang, S.L.; Xu, Z.H.; Ou-Yang, D.S.; Wang, Y.J.; Zhou, H.H. Effect of the gene dosage of CYP2C19 on diazepam metabolism in Chinese subjects. Clin. Pharmacol. Ther. 1999, 66, 642-646. [CrossRef] [PubMed]

9. Bertilsson, L.; Henthorn, T.K.; Sanz, E.; Tybring, G.; Säwe, J.; Villén, T. Importance of genetic factors in the regulation of diazepam metabolism: Relationship to S-mephenytoin, but not debrisoquin, hydroxylation phenotype. Clin. Pharmacol. Ther. 1989, 45 , 348-355. [CrossRef] [PubMed]

10. Skryabin, V.Y.; Zastrozhin, M.S.; Torrado, M.V.; Grishina, E.A.; Ryzhikova, K.A.; Shipitsyn, V.V.; Galaktionova, T.E.; Sorokin, A.S.; Bryun, E.A.; Sychev, D.A. How do CYP2C19* 2 and CYP2C19* 17 genetic polymorphisms affect the efficacy and safety of diazepam in patients with alcohol withdrawal syndrome? Drug Metab. Pers. Ther. 2020, 35, 84-92. [CrossRef] [PubMed]

11. Boddu, S.H.; Kumari, S. A Short Review on the Intranasal Delivery of Diazepam for Treating Acute Repetitive Seizures. Pharmaceutics 2020, 12, 1167. [CrossRef] [PubMed]

12. Rogawski, M.A.; Heller, A.H. Diazepam buccal film for the treatment of acute seizures. Epilepsy Behav. 2019, $101,106537$. [CrossRef] [PubMed]

13. Greenblatt, D.; Arendt, R.; Abernethy, D.R.; Giles, H.; Sellers, E.; Shader, R. In vitro quantitation of benzodiazepine lipophilicity: Relation to in vivo distribution. BJA Br. J. Anaesth. 1983, 55, 985-989. [CrossRef] [PubMed]

14. Anderson, G.D.; Saneto, R.P. Current oral and non-oral routes of antiepileptic drug delivery. Adv. Drug Deliv. Rev. 2012, 64, 911-918. [CrossRef]

15. Moolenaar, F.; Bakker, S.; Visser, J.; Huizinga, T. Biopharmaceutics of rectal administration of drugs in man IX. Comparative biopharmaceutics of diazepam after single rectal, oral, intramuscular and intravenous administration in man. Int. J. Pharm. 1980, 5, 127-137. [CrossRef]

16. Maglalang, P.D.; Rautiola, D.; Siegel, R.A.; Fine, J.M.; Hanson, L.R.; Coles, L.D.; Cloyd, J.C. Rescue therapies for seizure emergencies: New modes of administration. Epilepsia 2018, 59, 207-215. [CrossRef] [PubMed]

17. Wermeling, D.P.H.; Miller, J.L.; Archer, S.M.; Manaligod, J.M.; Rudy, A.C. Bioavailability and pharmacokinetics of lorazepam after intranasal, intravenous, and intramuscular administration. J. Clin. Pharmacol. 2001, 41, 1225-1231. [CrossRef]

18. Vyas, T.K.; Shahiwala, A.; Marathe, S.; Misra, A. Intranasal drug delivery for brain targeting. Curr. Drug Deliv. 2005, 2, 165-175. [CrossRef]

19. Schwarz, J.S.; Weisspapir, M.R.; Friedman, D.I. Enhanced transdermal delivery of diazepam by submicron emulsion (SME) creams. Pharm. Res. 1995, 12, 687-692. [CrossRef]

20. Mehmood, Y. Preparation of diazipam delayed release patch, for anxiolytic treatment. Int. J. 2014, 3, $19-23$.

21. Xu, Q.; Zan, Y.; Gao, C. Preparation of diazepam transdermal gel and its bioavailability. Zhejiang Da Xue Xue Bao Yi Xue Ban =J. Zhejiang Univ. Med Sci. 2012, 41, 441-444.

22. Cottura, N.; Howarth, A.; Rajoli, R.K.; Siccardi, M. The Current Landscape of Novel Formulations and the Role of Mathematical Modeling in Their Development. J. Clin. Pharmacol. 2020, 60, S77-S97. [CrossRef] [PubMed]

23. Jones, H.; Chen, Y.; Gibson, C.; Heimbach, T.; Parrott, N.; Peters, S.; Snoeys, J.; Upreti, V.; Zheng, M.; Hall, S. Physiologically based pharmacokinetic modeling in drug discovery and development: A pharmaceutical industry perspective. Clin. Pharmacol. Ther. 2015, 97, 247-262. [CrossRef]

24. Teorell, T. Kinetics of distribution of substances administered to the body, I: The extravascular modes of administration. Arch. Int. De Pharmacodyn. Et De Ther. 1937, 57, 205-225.

25. Poulin, P.; Theil, F.-P. Prediction of pharmacokinetics prior to in vivo studies. II. Generic physiologically based pharmacokinetic models of drug disposition. J. Pharm. Sci. 2002, 91, 1358-1370. [CrossRef] 
26. Theil, F.-P.; Guentert, T.W.; Haddad, S.; Poulin, P. Utility of physiologically based pharmacokinetic models to drug development and rational drug discovery candidate selection. Toxicol. Lett. 2003, 138, 29-49. [CrossRef]

27. Edginton, A.N.; Theil, F.-P.; Schmitt, W.; Willmann, S. Whole body physiologically-based pharmacokinetic models: Their use in clinical drug development. Expert Opin. Drug Metab. Toxicol. 2008, 4, 1143-1152. [CrossRef] [PubMed]

28. Rowland, M.; Peck, C.; Tucker, G. Physiologically-based pharmacokinetics in drug development and regulatory science. Annu. Rev. Pharmacol. Toxicol. 2011, 51, 45-73. [CrossRef] [PubMed]

29. De Buck, S.S.; Mackie, C.E. Physiologically based approaches towards the prediction of pharmacokinetics: In vitro-in vivo extrapolation. Expert Opin. Drug Metab. Toxicol. 2007, 3, 865-878. [CrossRef]

30. Rasool, M.F.; Läer, S. Development and evaluation of a physiologically based pharmacokinetic model to predict carvedilolparoxetine metabolic drug-drug interaction in healthy adults and its extrapolation to virtual chronic heart failure patients for dose optimization. Expert Opin. Drug Metab. Toxicol. 2021, 17, 717-724. [CrossRef] [PubMed]

31. Jamei, M.; Marciniak, S.; Feng, K.; Barnett, A.; Tucker, G.; Rostami-Hodjegan, A. The Simcyp ${ }^{\circledR}$ population-based ADME simulator. Expert Opin. Drug Metab. Toxicol. 2009, 5, 211-223. [CrossRef] [PubMed]

32. Zhuang, X.; Lu, C. PBPK modeling and simulation in drug research and development. Acta Pharm. Sin. B 2016, 6, 430-440. [CrossRef]

33. Jamei, M.; Turner, D.; Yang, J.; Neuhoff, S.; Polak, S.; Rostami-Hodjegan, A.; Tucker, G. Population-based mechanistic prediction of oral drug absorption. AAPS J. 2009, 11, 225-237. [CrossRef] [PubMed]

34. Tsiros, P.; Bois, F.Y.; Dokoumetzidis, A.; Tsiliki, G.; Sarimveis, H. Population pharmacokinetic reanalysis of a Diazepam PBPK model: A comparison of Stan and GNU MCSim. J. Pharmacokinet. Pharmacodyn. 2019, 46, 173-192. [CrossRef] [PubMed]

35. Ji, B.; Liu, S.; Xue, Y.; He, X.; Man, V.H.; Xie, X.-Q.; Wang, J. Prediction of drug-drug interactions between opioids and overdosed benzodiazepines using physiologically based pharmacokinetic (PBPK) modeling and simulation. Drugs RD 2019, 19, 297-305. [CrossRef]

36. Gueorguieva, I.I.; Nestorov, I.A.; Rowland, M. Fuzzy simulation of pharmacokinetic models: Case study of whole body physiologically based model of diazepam. J. Pharmacokinet. Pharmacodyn. 2004, 31, 185-213. [CrossRef] [PubMed]

37. Rasool, M.F.; Khalid, S.; Majeed, A.; Saeed, H.; Imran, I.; Mohany, M.; Al-Rejaie, S.S.; Alqahtani, F. Development and Evaluation of Physiologically Based Pharmacokinetic Drug-Disease Models for Predicting Rifampicin Exposure in Tuberculosis and Cirrhosis Populations. Pharmaceutics 2019, 11, 578. [CrossRef]

38. Rasool, M.F.; Khalid, R.; Imran, I.; Majeed, A.; Saeed, H.; Alasmari, F.; Alanazi, M.M.; Alqahtani, F. Investigating the role of altered systemic albumin concentration on the disposition of theophylline in adult and pediatric patients with asthma by using the physiologically based pharmacokinetic approach. Drug Metab. Dispos. 2020, 48, 570-579. [CrossRef]

39. Drugbank (Diazepam Compound Summary). Available online: https://go.drugbank.com/drugs/DB00829 (accessed on 14 December 2020).

40. Pubchem (Diazepam Compound Summary). Available online: https://pubchem.ncbi.nlm.nih.gov/compound/Diazepam\# section=Computed-Properties (accessed on 6 January 2021).

41. Ye, M.; Nagar, S.; Korzekwa, K. A physiologically based pharmacokinetic model to predict the pharmacokinetics of highly protein-bound drugs and the impact of errors in plasma protein binding. Biopharm. Drug Dispos. 2016, 37, 123-141. [CrossRef]

42. Gonzalez, F.; Coughtrie, M.; Tukey, R. Goodman and Gilman's The Pharmacological Basis of Therapeutics; The McGraw-Hill Companies, Inc.: New York, NY, USA, 2006; pp. 71-92.

43. FDA (Valium Label). Available online: https://www.accessdata.fda.gov/drugsatfda_docs/label/2016/013263s094lbl.pdf (accessed on 15 January 2021).

44. Onof, S.; Hatanaka, T.; Miyazawa, S.; Tsutsui, M.; Aoyama, T.; Gonzalez, F.; Satoh, T. Human liver microsomal diazepam metabolism using cDNA-expressed cytochrome P450s: Role of CYP2B6, 2C19 and the 3A subfamily. Xenobiotica 1996, 26, 1155-1166. [CrossRef]

45. GDG Digitizer. GetData Graph Digitizer (2.26); GDG Digitizer: 2013. Available online: http://getdata-graph-digitizer.com, (accessed on 12 September 2021).

46. Gizurarson, S.; Gudbrandsson, F.K.; Jonsson, H.; BECHGAARD, E. Intranasal administration of diazepam aiming at the treatment of acute seizures: Clinical trials in healthy volunteers. Biol. Pharm. Bull. 1999, 22, 425-427. [CrossRef]

47. Ivaturi, V.D.; Riss, J.R.; Kriel, R.L.; Siegel, R.A.; Cloyd, J.C. Bioavailability and tolerability of intranasal diazepam in healthy adult volunteers. Epilepsy Res. 2009, 84, 120-126. [CrossRef]

48. Agarwal, S.K.; Kriel, R.L.; Brundage, R.C.; Ivaturi, V.D.; Cloyd, J.C. A pilot study assessing the bioavailability and pharmacokinetics of diazepam after intranasal and intravenous administration in healthy volunteers. Epilepsy Res. 2013, 105, 362-367. [CrossRef]

49. Cloyd, J.C.; Lalonde, R.L.; Beniak, T.E.; Novack, G.D. A single-blind, crossover comparison of the pharmacokinetics and cognitive effects of a new diazepam rectal gel with intravenous diazepam. Epilepsia 1998, 39, 520-526. [CrossRef]

50. Lau, S.; Slattery, J.T. Absorption of diazepam and lorazepam following intranasal administration. Int. J. Pharm. 1989, 54, 171-174. [CrossRef]

51. Friedman, H.; Greenblatt, D.J.; Peters, G.R.; Metzler, C.M.; Charlton, M.D.; Harmatz, J.S.; Antal, E.J.; Sanborn, E.C.; Francom, S.F. Pharmacokinetics and pharmacodynamics of oral diazepam: Effect of dose, plasma concentration, and time. Clin. Pharmacol. Ther. 1992, 52, 139-150. [CrossRef] [PubMed] 
52. Greenblatt, D.J.; Harmatz, J.S.; Friedman, H.; Locniskar, A.; Shader, R.I. A large-sample study of diazepam pharmacokinetics. Ther. Drug Monit. 1989, 11, 652-657. [CrossRef]

53. Rasool, M.F.; Ali, S.; Khalid, S.; Khalid, R.; Majeed, A.; Imran, I.; Saeed, H.; Usman, M.; Ali, M.; Alali, A.S. Development and evaluation of physiologically based pharmacokinetic drug-disease models for predicting captopril pharmacokinetics in chronic diseases. Sci. Rep. 2021, 11, 8589. [CrossRef] [PubMed]

54. Divoll, M.; Greenblatt, D.J.; Ochs, H.R.; Shader, R.I. Absolute bioavailability of oral and intramuscular diazepam: Effects of age and sex. Anesth. Analg. 1983, 62, 1-8. [CrossRef] [PubMed]

55. Ali, J.; Ali, M.; Baboota, S.; Kaur Sahni, J.; Ramassamy, C.; Dao, L. Potential of nanoparticulate drug delivery systems by intranasal administration. Curr. Pharm. Des. 2010, 16, 1644-1653. [CrossRef]

56. Choi, H.-G.; Jung, J.-H.; Ryu, J.-M.; Yoon, S.-J.; Oh, Y.-K.; Kim, C.-K. Development of in situ-gelling and mucoadhesive acetaminophen liquid suppository. Int. J. Pharm. 1998, 165, 33-44. [CrossRef]

57. Ugwoke, M.I.; Verbeke, N.; Kinget, R. The biopharmaceutical aspects of nasal mucoadhesive drug delivery. J. Pharm. Pharmacol. 2001, 53, 3-22. [CrossRef]

58. Arora, P.; Sharma, S.; Garg, S. Permeability issues in nasal drug delivery. Drug Discov. Today 2002, 7, 967-975. [CrossRef]

59. Schrier, L.; Zuiker, R.; Merkus, F.W.; Klaassen, E.S.; Guan, Z.; Tuk, B.; van Gerven, J.M.; van der Geest, R.; Groeneveld, G.J. Pharmacokinetics and pharmacodynamics of a new highly concentrated intranasal midazolam formulation for conscious sedation. Br. J. Clin. Pharmacol. 2017, 83, 721-731. [CrossRef]

60. Ivaturi, V.D. Intranasal and Rectal Diazepam for Rescue Therapy: Assessment of Pharmacokinetics and Tolerability; University of Minnesota: Minneapolis, MN, USA, 2010.

61. Hou, H.; Siegel, R.A. Enhanced permeation of diazepam through artificial membranes from supersaturated solutions. J. Pharm. Sci. 2006, 95, 896-905. [CrossRef]

62. FDA. Nasal Spray and Inhalation Solution, Suspension, and Spray Drug Products—Chemistry, Manufacturing and Controls Documentation; FDA: New Hampshire, MD, USA, 2002.

63. Hogan, R.E.; Tarquinio, D.; Sperling, M.R.; Klein, P.; Miller, I.; Segal, E.B.; Rabinowicz, A.L.; Carrazana, E. Pharmacokinetics and safety of VALTOCO (NRL-1; diazepam nasal spray) in patients with epilepsy during seizure (ictal/peri-ictal) and nonseizure (interictal) conditions: A phase 1, open-label study. Epilepsia 2020, 61, 935-943. [CrossRef]

64. Detyniecki, K.; Van Ess, P.J.; Sequeira, D.J.; Wheless, J.W.; Meng, T.C.; Pullman, W.E. Safety and efficacy of midazolam nasal spray in the outpatient treatment of patients with seizure clusters-A randomized, double-blind, placebo-controlled trial. Epilepsia 2019, 60, 1797-1808. [CrossRef] [PubMed]

65. Anderson, M. Buccal midazolam for pediatric convulsive seizures: Efficacy, safety, and patient acceptability. Patient Prefer. Adherence 2013, 7, 27. [CrossRef] [PubMed]

66. Sarma, A.K.; Khandker, N.; Kurczewski, L.; Brophy, G.M. Medical management of epileptic seizures: Challenges and solutions. Neuropsychiatr. Dis. Treat. 2016, 12, 467. [PubMed]

67. Pellock, J.M. Safety of Diastat ${ }^{\circledR}$, a rectal gel formulation of diazepam for acute seizure treatment. Drug Saf. 2004, 27, 383-392. [CrossRef]

68. Chetty, M.; Rose, R.H.; Abduljalil, K.; Patel, N.; Lu, G.; Cain, T.; Jamei, M.; Rostami-Hodjegan, A. Applications of linking PBPK and PD models to predict the impact of genotypic variability, formulation differences, differences in target binding capacity and target site drug concentrations on drug responses and variability. Front. Pharmacol. 2014, 5, 258. [CrossRef] 